\title{
Penerapan Activity Based Costing System Dalam Menentukan Harga Pokok Jasa Pemasangan GPS pada PT SLI
}

\author{
${ }^{1}$ Beta Nur Hidayah, ${ }^{2}$ Nanik Kustiningsih \\ 1-2 Jurusan Akuntansi, Sekolah Tinggi Ilmu Ekonomi Mahardhika
}

Article history

Received: 08-05-2021

Revised: 24-06-2021

Accepted: 03-07-2021

*Corresponding Author:

Beta Nur Hidayah

Nanik Kustiningsih

Jurusan Akuntansi

Sekolah Tinggi Ilmu

Ekonomi Mahardhika

Email:

betanurhidayah99@gmail.c om

\begin{abstract}
Abstrak: Meningkatnya persaingan yang terjadi pada industri jasa Global Positioning System (GPS) mengharuskan PT SLI untuk membuat strategi baru dalam memenangkan persaingan yaitu dengan meningkatkan kualitas pelayanan dan menekan harga jual. Semakin rendah harga jual maka tingkat penjualan jasa akan semakin tinggi. Metode activity based costing system (ABC) dinilai sangat efektif dan akurat dalam menentukan harga pokok produksi karena pembebanan biayanya berdasarkan aktivitas dan perilaku aktivitas yang terjadi. Tujuan penelitian ini adalah untuk membandingkan harga pokok jasa yang dihitung menggunakan metode activity based costing system dengan metode akuntansi biaya tradisional yang diterapkan pada PT SLI. Penelitian ini menggunakan jenis penelitian deskriptif komparatif dengan objek PT SLI dan subjek semua paket gps yang ada di PT SLI yaitu W, E dan G. Sumber data yang digunakan adalah data primer dan data sekunder dengan dua teknik pengumpulan data yaitu penelitian lapangan (field research) dan penelitian kepustakaan (library research). Hasil penelitian menunjukkan bahwa adanya selisih lebih rendah harga pokok jasa pemasangan gps yang dihitung dengan metode activity based costing system daripada metode yang diterapkan oleh PT SLI. PT SLI sebaiknya mempertimbangkan metode activity based costing system dalam menentukan harga pokok jasa untuk pengambilan keputusan dimasa yang akan datang
\end{abstract}

\section{Kata Kunci : Activity Based Costing System, Akuntansi Biaya Tradisional, Harga Pokok Produksi}

\section{PENDAHULUAN}

Perusahaan Global Positioning System (GPS) merupakan perusahaan yang bergerak pada bidang penyedia jasa tracking system yang dipasang pada berbagai kendaraan seperti alat-alat berat, truk, bis, mobil dan motor. Meningkatnya jumlah perusahaan pada industri ini menimbulkan persaingan yang ketat antar perusahaan gps, sehingga manajemen perusahaan dituntut untuk meningkatkan efektifitas dan efisiensi dalam mengelolah perusahaan tersebut dengan baik dan memiliki daya saing yang tinggi. Untuk mencapai keberhasilan dalam persaingan, perusahaan pada industri ini harus meningkatkan kualitas pelayanan dan harga. Kualitas jasa atau kualitas pelayanan merupakan sebuah kondisi dinamis yang realisasinya dengan sebuah produk, jasa, sumber daya manusia, proses serta lingkungan yang memenuhi atau melebihi harapan (Tjiptono dan Chandra, 2016). Hal ini menunjukkan bahwa pelanggan atau calon pelanggan akan tertarik dengan produk yang kita tawarkan apabila kualitas dalam pelayanan kita memenuhi atau melebihi ekspektasi mereka, sehingga mereka merasa puas. Durasi pemasangan gps yang singkat, alat gps yang kuat, kecepatan tanggapan dalam menangani gps yang bermasalah merupakan contoh kualitas pelayanan yang diberikan perusahaan gps kepada pelanggan.

Selain kualitas pelayanan, harga merupakan faktor yang berpengaruh dalam 
menentukan daya tarik pelanggan atau calon pelanggan. Harga merupakan jumlah nominal yang harus dibayarkan para konsumen untuk jasa yang telah mereka gunakan kepada penyedia jasa tersebut. Apabila terdapat dua penyedia jasa yang memiliki kualitas pelayanan yang sama namun dengan harga yang berbeda maka para konsumen akan lebih memilih penyedia jasa yang harganya lebih rendah. Harga merupakan faktor utama yang mempengaruhi pilihan pembeli karena harga cukup berperan dalam menentukan keputusan pembelian. Harga akan mempengaruhi keputusan pembelian apabila harga pada produk tersebut seduai dengan kualitas dan manfaatnya serta masih dianggap terjangkau oleh konsumen (Akbar dalam Hidayat, 2018). Untuk itu manajemen perusahaan gps ini harus memberikan kualitas layanan yang memuaskan namun dengan harga yang terjangkau, sehingga perlu adanya strategi-strategi untuk menang dalam persaingan ini, salah satunya adalah dengan menekan harga jual produk. Dalam menetapkan harga jual suatu produk terdapat faktor-faktor yang mempengaruhi yaitu faktor yang berkaitandengan laba yang diharapkan, faktor yang berkaitan dengan produk atau penjualan produk dan faktor yang berkaitan dengan biaya (Mulyadi dalam Narko, 2016). Salah satunya ialah harga pokok produksi, Harga pokok produksi sangat berpengaruh dalam menentukan besarnya harga jual produk. Harga pokok produksi merupakan segala biaya yang dikeluarkan untuk memproduksi barang atau jasa dalam periode yang bersangkutan, atau dengan kata lain, harga pokok produksi adalah biaya yang dikeluarkan untuk memperoleh barang jadi yang siap jual (Mulyadi, 2015). Dengan diperkuat pernyataan oleh Kindangen dkk. (2018) bahwa harga pokok produksi merupakan biaya-biaya yang digunakan dalam menghasilkan barang atau jasa pada proses produksi. Harga pokok produksi mempunyai manfaat yang sangat besar sehingga perhitungan harga pokok produksi harus akurat. Penetapan biaya yang dianggap tepat akan menghasilkan harga pokok yang akurat. Biaya adalah penurunan manfaat ekonomi pada periode akuntansi tertentu yang berupa arus keluar aset atau kewajiban yang menyebabkan penurunan suatu ekuitas yang tidak menyertakan pembagian investor (Kustiningsih N. dkk., 2017). Sehingga perusahaan diharapkan serius dalam menentukan harga pokok produk. Semakin rendahnya harga dengan kualitas pelayanan yang dianggap memuaskan konsumen, maka semakin tinggi pula tingkat penjualan pada perusahaan jasa ini.

Sebagai komponen biaya produk, sistem akuntansi biaya tradisional digunakan untuk menghitung harga pokok produksi (Mulyadi dalam Kustiningsih N. dkk., 2017). Sistem akuntansi biaya tradisional hanya menyajikan data rinci mengenai biaya produksi atau biaya yang dikeluarkan dalam proses produksi. Metode tradisional yang digunakan perusahaan dalam menentukan harga pokok dianggap kurang akurat karena sistem akuntansi biaya tradisional dalam pembebanan biaya menggunakan pembebanan biaya menyeluruh atau per departemen. Hal tersebut menimbulkan under costing atau over costing pada produk karena tidak menggambarkan biaya yang sesungguhnya terjadi sehingga hal ini berdampak pada laba yang akan didapat perusahaan. Selain itu, terjadinya distorsi biaya akan berpengaruh dalam pengambilan keputusan, perencanaan mendatang dan pengendalian perusahaan.

Berbeda dengan sistem akuntansi biaya tradisional, metode activity based costing system atau yang biasa disebut dengan metode ABC merupakan suatu sistem dalam penentuan biaya yang berbasis aktivitas, sehingga dilihat secara umum metode activity based costing system menggunakan dua tahap dalam pendekatan yang hampir sama namun lebih umum daripada sistem biaya tradisional (Kustiningsih N. dkk., 2017). Metode activity based costing system dianggap lebih aktif dalam penentuan harga pokok gps karena pembebanan biaya berdasarkan aktivitas pada PT SLI dan mengelompokkan biaya berdasarkan perilaku yang timbul dari aktivitas dalam menentukan harga jasa pemasangan gps. Dapat dilihat bahwa metode activity based costing system memberikan informasi 
mengenai perhitungan biaya yang lebih baik serta harga pokok produk secara akurat untuk kepentingan manajemen perusahaan, yaitu dapat mengalokasikan biaya berdasarkan aktivitas-aktivitas yang dilakukan. Sehingga diharapkan sistem ini dapat memberikan kemudahan manajemen perusahaan untuk mengelola perusahaan dalam memperoleh pemahaman yang lebih baik terhadap keunggulan, kekuatan dan kelemahan perusahaan serta membuat keputusan yang lebih baik dengan pengukuran yang lebih akurat. Activity based costing system merupakan solusi yang dilakukan oleh perusahaan untuk memperoleh informasi akuntansi yang relevan dalam variasi kondisi, menurut harapan sistem ini dapat diterapkan pada PT SLI dengan kesesuaian kebijakan manajemen perusahaan. Oleh karena itu, penulis ingin meneliti apakah terdapat perbedaan dari hasil perhitungan harga pokok jasa pemasangan gps menggunakan metode akuntansi biaya tradisional pada PT SLI dengan metode Activity Based Costing System

\section{METODE}

Penelitian ini menggunakan metode deskriptif komparatif untuk mendapatkan hasil penelitian yang akan dianalisis. Penelitian deskriptif komparatif merupakan penelitian yang akan membandingkan tarif jasa pemasangan gps sebelum dan sesudah menggunakan metode activity based costing system. Objek dalam penelitian ini adalah PT SLI yaitu perusahaan penyedia jasa pemasangan gps dengan subjek yang diteliti adalah macammacam paket pemasangan gps pada PT SLI meliputi paket w, paket e dan paket g. Dalam pengambilan sampel pada penelitian ini menggunakan teknik sampel purposive yaitu salah satu teknik dalam penentuan sampel atas peninjauan tertentu (Sugiyono, 2017). Pada penelitian ini sampel diambil atas perbedaan menurut alat gpsnya yaitu w, e dan $\mathrm{g}$.

Data primer dan data sekunder merupakan sumber data yang digunakan pada penelitian ini. Data primer merupakan data yang didapatkan melalui pengamatan secara langsung pada PT SLI, sedangkan data sekunder merupakan data yang diperoleh dari PT SLI dalam mengumpulkan data-data yang berkaitan. Dengan dua teknik pengumpulan data yaitu penelitian lapangan (field research) dan penelitian kepustakaan (library research). Pada penelitian lapangan (field research) peneliti mendapatkan data dengan teknik wawancara yaitu proses untuk memperoleh informasi dalam mengumpulkan data dari pihak perusahaan yang diwawancarai. Peneliti memberikan beberapa pertanyaan kepada pihak pimpinan dan beberapa staf perusahaan untuk mendapatkan informasi yang terkait dengan media teleconference zoom akibat adanya pandemi covid-19, selain dengan teknik wawancara juga dilakukan dengan teknik dokumentasi yaitu peneliti mengambil serta mengumpulkan informasi penting dari perusahaan yang terkait dalam penelitian seperti biaya yang dikeluarkan oleh PT SLI, jumlah stok persediaan gps, jumlah gps yang terjual dan sebagainya yang dikirimkan melalui email. Sedangkan penelitian kepustakaan (library research) merupakan penelitian yang dilakukan dengan cara menelaah buku, literatur catatan serta berbagai laporan yang berkaitan.

Metode analisis dalam penelitian ini adalah metode deskriptif yaitu analisis data dengan menggambarkan data yang terkumpul berdasarkan penilaian objektif untuk diuraikan

\section{PEMBAHASAN}

Menurut Simamora dalam Pulungan Z.R., (2017) dalam prosedur pembebanan biaya overhead dengan menggunakan activity based costing system ada dua tahap kegiatan. Pada tahap pertama ini dilakukan pembebanan biaya overhead terhadap aktivitas-aktivitas melalui lima tahap yaitu pengidentifikasian aktivitas-aktivitas; penentuan biaya terkait masing-masing aktivitas; pengelompokkan aktivitas yang diidentifikasi dalam empat kelompok yaitu unit level activities, batch level activities, product sustaining activities dan 
facility sustaining activities; penggabungan biaya dari aktivitas yang telah dikelompokkan dan perhitungan tarif pada tiap kelompok (homogen cost pool rate). Sedangkan pada tahap kedua yaitu pembebanan biaya aktivitas pada produk. Apabila tarif tiap kelompok aktivitas telah diketahui dan selanjutnya perhitungan biaya overhead yang dibebankan pada produk dengan rumus: perhitungan tarif kelompok x jumlah konsumsi tiap produk.

Cost Driver adalah faktor yang dapat menggambarkan berapa besar penggunaan biaya-biaya overhead. Penentuan cost driver sangat dibutuhkan untuk perusahaan jasa, sebab mempunyai diversifikasi produk yang tinggi. Penentuan pada jumlah cost driver yang diperlukan didasarkan pada keakuratan laporan biaya produk yang diinginkan serta kompleksitas komposisi output perusahaan. Semakin banyak cost driver yang digunakan semakin tinggi juga tingkat akurat laporan biaya atau semakin tinggi tingkat keakuratan maka semakin banyak pula cost driver yang dibutuhkan (Cooper dan Kaplan dalam Pulungan Z. R., 2017). Hal terpenting dalam activity based costing system adalah mengidentifikasi cost driver, faktor penting dalam memilih cost driver yang tepat yaitu degree of correlation, cost measurement, behavioural effects dan cost pool. Cost pool merupakan aktivitas tunggal atau kelompok yang biayanya diakumulasikan dan mendistribusikan biaya tersebut pada produk. Dalam perhitungan pool rate (tarif pool) dapat menggunakan rumus jumlah biaya cost pool dibagi kapasitas activity driver.

Activity Based Costing System menjadikan aktivitas sebagai pusat kegiatan, data mengenai aktivitas tersebut dicatat, diukur serta disediakan dalam shared database pada sistem ini. Aktivitas-aktivitas tersebut dapat ditemukan di perusahaan jasa, dagang, manufaktur, organisasi-organisasi sektor publik atau nirlaba, sehingga sistem ini dapat digunakan oleh berbagai jenis organisasi tersebut (Badira, 2017). Dalam sistem ini tidak hanya terfokus pada perhitungan harga pokok produk, namun juga mencakup perspektif yang lebih luas lagi, seperti mengurangi biaya melalui pengelolaan aktivitas. Dalam penerapan sistem Activity based costing pada perusahaan jasa, ada tiga hal yang perlu diperhatikan. Pertama, identifikasi dan perhitungan biaya yaitu melakukan identifikasi dan menghitung dengan memberikan harga pada setiap aktivitas yang dilakukan sehingga dapat memberikan kesempatan dalam pengoprasian agar lebih efisien. Kedua, permasalahan khusus yaitu permasalahan serupa yang terjadi antar perusahaan seperti perusahaan manufaktur dengan perusahaan jasa, yaitu sulitnya pengalokasian biaya pada aktivitasaktivitas yang dilakukan. Selain itu, jasa tidak dapat dimasukkan pada persediaan seperti perusahaan manufaktur, karena kapasitas yang tersedia namun tidak dapat digunakan untuk memunculkan biaya yang tidak dapat dihindari. Ketiga, keragaman output yaitu kesulitan yang muncul pada perusahaan jasa adalah pengidentifikasian output yang ada, perbedaan yang ada dalam perusahaan jasa adalah aktivitas-aktivitas pendukung pada hal yang berbeda yang sulit untuk ditentukan.

Berdasarkan data yang peneliti peroleh dari PT SLI sehubungan dengan perhitungan harga pokok pemasangan gps dan penentuan harga jual jasa pemasangan gps. Dalam membandingkan activity based costing system, peneliti mengambil data-data yang dibutuhkan dalam penentuan harga jual jasa pemasangan gps, yaitu antara lain biaya pemasangan gps dan pendukung, jumlah stok alat gps, jumlah penjualan pemasangan gps dan harga jasa pemasangan gps pada bulan januari, februari dan maret 2021.

Tabel 1 Jumlah Stok Tersedia dan Terjual Jan-Mar 2021

\begin{tabular}{ccccccc}
\hline \multirow{2}{*}{ Paket } & \multicolumn{2}{c}{ Januari } & \multicolumn{2}{c}{ Februari } & \multicolumn{2}{c}{ Maret } \\
\cline { 2 - 7 } & Tersedia & Terjual & Tersedia & Terjual & Tersedia & Terjual \\
\hline W & 20 & 17 & 20 & 15 & 40 & 37 \\
\hline E & 20 & 15 & 20 & 18 & 25 & 22 \\
\hline G & 20 & 14 & 20 & 14 & 25 & 21 \\
\hline
\end{tabular}




\begin{tabular}{lllllll}
\hline Jumlah & 60 & 46 & 60 & 47 & 90 & 80 \\
\hline
\end{tabular}

Sumber: data diolah

Tabel 2 Pendapatan Jasa Pemasangan GPS Jan-Mar 2021

Paket Unit Terjual Harga Jual Pendapatan Jasa (Rp)

\begin{tabular}{crrr}
\multicolumn{4}{c}{$(\mathrm{Rp})$} \\
\hline $\mathrm{W}$ & 69 & 750.000 & 51.750 .000 \\
\hline $\mathrm{E}$ & 55 & 900.000 & 49.500 .000 \\
\hline $\mathrm{G}$ & 49 & 1.250 .000 & 61.250 .000 \\
\hline Jumlah & & & 162.500 .000 \\
\hline
\end{tabular}

Sumber: data diolah

Tabel 1 menjelaskan bahwa jumlah stok paket w yang tersedia 80 unit dan yang terjual sebesar 69 unit. Jumlah paket e yang tersedia sebesar 65 unit dengan jumlah terjual 55 unit, sedangkan untuk paket $g$ yang tersedia juga sebesar 65 unit dengan jumlah terjual 49 unit. Pada tabel 1 juga dapat dilihat bahwa terjadinya kenaikan jumlah penjualan, hal tersebut dikarenakan pada bulan maret banyak rental mobil atau sepeda motor yang mempersiapkan unit mereka untuk dipasang gps mengingat sudah mendekati ramadhan dan idul fitri.

Tabel 2 menjelaskan bahwa pendapatan yang diterima selama bulan Januari hingga Maret 2021 untuk paket w sebesar Rp 51.750.000, paket e sebesar Rp 49.500 .000 sedangkan untuk paket g sebesar Rp 61.250.000 dengan total pendapatan selama tiga bulan sebesar Rp 162.500.000.

\section{Perhitungan Harga Pokok Jasa Pemasangan GPS Menggunakan Metode Activity Based Costing System}

Dalam menentukan harga pokok jasa pemasangan gps menggunakan activity based costing system perlu melalui langkah-langkah yang harus dilakukan. Langkah pertama ialah pengidentifikasian biaya dan aktivitas yang dilakukan. Biaya-biaya yang diidentifikasi adalah biaya langsung yang terjadi pada departemen pemasangan gps maupun tidak langsung. Aktivitas yang dilakukan pada departemen pemasangan gps merupakan aktivitas yang berhubungan langsung dengan pemasangan gpsnya, dilanjutkan dengan pengidentifikasian aktivitas biaya tidak langsung dan mengelompokkan pada level aktivitasnya.

Tabel 3 Biaya Langsung PT SLI bulan Jan-Mar 2021

\begin{tabular}{ccrrr}
\hline No. & Biaya Langsung & Paket W $(\mathrm{Rp})$ & Paket E $(\mathrm{Rp})$ & Paket G (Rp) \\
\hline 1 & Teknisi & 2.415 .000 & 1.925 .000 & 1.715 .000 \\
\hline 2 & BBM & 300.000 & 200.000 & 100.000 \\
\hline Biaya Langsung Tiap Bulan & 2.715 .000 & 2.125 .000 & 1.815 .000 \\
\hline \multicolumn{2}{r}{ Total Biaya Langsung } & & 6.655 .000 & \\
\hline
\end{tabular}

Sumber: data diolah

Tabel 4 Aktivitas dan Level Aktivitas

\begin{tabular}{clll}
\hline No. & \multicolumn{1}{c}{ Aktivitas } & Level Aktivitas & \multicolumn{1}{c}{ Cost Driver } \\
\hline 1 & Insentif & Unit Level & Jumlah Unit Terjual \\
\hline 2 & Lisensi Server & Unit Level & Jumlah Unit Terjual \\
\hline 3 & Pemasaran & Product Sustaining & Jumlah Unit Tersedia \\
\hline 4 & Perlengkapan Kantor & Facility Sustaining & Luas Kantor \\
\hline 5 & Sewa, Listrik dan Air & Facility Sustaining & Jumlah Pengguna \\
\hline 6 & Wifi dan Telepon & Facility Sustaining & Jumlah Pengguna \\
\hline 7 & Gaji Karyawan & Facility Sustaining & Jumlah Hari Kerja \\
\hline
\end{tabular}

Sumber: data diolah

Tabel 3 menjelaskan bahwa yang termasuk dalam biaya langsung adalah bonus teknisi dan bbm dengan total sebesar Rp 6.655.000. 
Tabel 4 menjelaskan bahwa yang termasuk biaya tidak langsung adalah aktivitas yang terjadi seperti insentif; lisensi server; pemasaran; perlengkapan kantor; sewa, listrik dan air; wifi dan telepon serta gaji karyawan. Dari aktivitas tersebut dikelompokkan pada setiap level aktivitasnya yaitu unit level, product sustaining dan facility sustaining Dari level aktivitas tersebut diarahkan kepada cost driver yaitu menggambarkan berapa besar biaya overhead dibebankan. Cost Driver pada level aktivitas unit level digambarkan pada jumlah unit yang terjual, product sustaining digambarkan pada jumlah unit yang tersedia. Sedangkan pada facility sustaining, Cost Driver dibagi pada luas kantor dan jumlah hari kerja karena tidak berkaitan dengan jenis produk.

Setelah diarahkan pada cost driver maka mengelompokkan cost driver tersebut ke dalam cost pool. Cost pool digunakan dalam menentukan tarif BOP per unit pada cost driver yang dihitung berdasarkan kelompok aktivitas. Aktivitas-aktivitas yang terdapat pada tabel 4 akan dikelompokkan menurut cost drivernya.

Cost pool I berisi kelompok dengan cost driver jumlah unit terjual seperti aktivitas insentif dan lisensi server. Cost pool II berisi kelompok dengan cost driver jumlah unit tersedia seperti aktivitas pemasaran. Untuk cost pool III berisi kelompok dengan cost driver luas kantor seperti aktivitas perlengkapan kantor. Cost pool IV berisi kelompok dengan cost driver jumlah pengguna seperti aktivitas sewa, listrik dan air serta aktivitas wifi dan telepon. Sedangkan untuk cost pool V memuat kelompok aktivitas dengan cost driver jumlah hari kerja yaitu aktivitas gaji karyawan.

Langkah kedua yaitu pembebanan Biaya Overhead, dimulai dari merincikan biaya per aktivitas pada setiap kelompok cost pool dan mengalokasikan pemakaian cost driver pada bulan januari, februari hingga maret 2021.

Tabel 5 Rincian Biaya per Aktivitas Cost Pool

\begin{tabular}{|c|c|c|c|}
\hline Aktivitas & Jan (Rp) & Feb (Rp) & $\operatorname{Mar}(\mathrm{Rp})$ \\
\hline \multicolumn{4}{|l|}{$\begin{array}{l}\text { Cost Pool I } \\
\text { Insentif: }\end{array}$} \\
\hline Karyawan & 1.150 .000 & 1.175 .000 & 2.000 .000 \\
\hline \multirow{2}{*}{$\begin{array}{l}\text { Lisensi Server } \\
\text { Total Cost Pool I }\end{array}$} & 2.622 .000 & 2.679 .000 & 4.560 .000 \\
\hline & & & 14.186 .000 \\
\hline \multicolumn{4}{|l|}{$\begin{array}{l}\text { Cost Pool II } \\
\text { Pemasaran. }\end{array}$} \\
\hline Iklan dan Promosi & 450.000 & 350.000 & 350.000 \\
\hline Total Cost Pool II & & & 1.150 .000 \\
\hline \multicolumn{4}{|l|}{ Cost Pool III } \\
\hline ATK dan Kebersihan & 40.000 & 40.000 & 40.000 \\
\hline Total Cost Pool III & & & 120.000 \\
\hline \multicolumn{4}{|l|}{ Cost Pool IV } \\
\hline Sewa, Listrik dan Air & 1.500 .000 & 1.500 .000 & 1.500 .000 \\
\hline Wifi dan Telepon & 350.000 & 350.000 & 350.000 \\
\hline Total Cost Pool IV & & & 5.550 .000 \\
\hline \multicolumn{4}{|l|}{$\begin{array}{l}\text { Cost Pool V } \\
\text { Penggajian: }\end{array}$} \\
\hline Karyawan & 11.250 .000 & 10.350 .000 & 11.700 .000 \\
\hline Total Cost Pool IV & & & 33.300 .000 \\
\hline
\end{tabular}

Sumber: data diolah

Tabel 6 Pengalokasian Pemakaian Cost Driver Jan-Mar 2021

\begin{tabular}{clc}
\hline No. & \multicolumn{1}{c}{ Cost Driver } & Jumlah \\
\hline 1 & Alokasi jumlah unit terjual: & \\
& Paket W & 69 \\
& Paket E & 55 \\
\hline
\end{tabular}




\begin{tabular}{|c|c|c|}
\hline & Paket G & 49 \\
\hline & Total & 173 \\
\hline \multirow[t]{5}{*}{2} & Alokasi jumlah unit tersedia: & \\
\hline & Paket W & 80 \\
\hline & Paket E & 65 \\
\hline & Paket G & 65 \\
\hline & Total & 210 \\
\hline \multirow[t]{5}{*}{3} & Alokasi luas kantor: & \\
\hline & Paket W & 2333 \\
\hline & Paket E & 2333 \\
\hline & Paket G & 2334 \\
\hline & Total & 7000 \\
\hline \multirow[t]{5}{*}{4} & Alokasi jumlah pengguna: & \\
\hline & Paket W & 3 \\
\hline & Paket E & 2 \\
\hline & Paket G & 2 \\
\hline & Total & 7 \\
\hline \multirow[t]{5}{*}{5} & Alokasi jumlah hari kerja: & \\
\hline & Paket W & 24,6 \\
\hline & Paket E & 24,6 \\
\hline & Paket G & 24,8 \\
\hline & Total & 74 \\
\hline
\end{tabular}

Sumber: data diolah

Berdasarkan uraian diatas dapat dilihat bahwa pada tabel 5 menjelaskan ringkasan biaya per aktivitas cost pool. Jumlah biaya pada Cost pool I sebesar Rp 14.186.000, Cost pool II sebesar Rp 1.150.000, Cost pool III sebesar Rp 120.000, Cost pool IV sebesar Rp 5.550.000 dan Cost pool V sebesar Rp 33.300.000.

Sedangkan pada tabel 6 menjelaskan mengenai pengalokasian pemakaian cost driver. Cost driver yang pertama adalah jumlah unit terjual yang berarti jumlah paket gps yang terjual yaitu sebesar 173 unit. Kedua, cost driver jumlah unit tersedia yaitu sebesar 210. Cost driver luas kantor sebesar $7000 \mathrm{~m} 2$, cost driver jumlah pengguna sebesar 7 orang yaitu jumlah karyawan kantor pada PT SLI dan cost driver jumlah hari kerja yaitu 74 hari (Januari, Februari dan Maret).

Langkah ketiga yaitu menentukan tarif kelompok cost pool per unitnya. Dalam menentukan tarif tersebut digunakan rumus jumlah aktivitas dibagi cost driver. Kemudian membebankan biaya pada jasa menggunakan tarif tersebut dan ukuran aktivitas. Pada tahap ini perhitungan pembebanan Overhead dari setiap cost pool menggunakan rumus: tarif kelompok x unit cost driver yang dipakai. Sehingga penentuan harga pokok jasa pemasangan gps dapat dilakukan.

Tabel 7 Penentuan Tarif Kelompok Cost Pool per Unit

\begin{tabular}{rrcr}
\hline Cost Pool & Tarif Cost Pool $(\mathrm{Rp})$ & Cost Driver & Tarif per Unit \\
\hline Cost Pool I & 14.186 .000 & 173 & 82.000 \\
\hline Cost Pool II & 1.150 .000 & 210 & 5.476 \\
\hline Cost Pool III & 120.000 & 7000 & 17 \\
\hline Cost Pool IV & 5.550 .000 & 7 & 792.857 \\
\hline Cost Pool V & 33.300 .000 & 74 & 450.000 \\
\hline
\end{tabular}

Sumber: data diolah

Tabel 8 Perhitungan Harga Pokok Jasa Pemasangan GPS dengan Metode Activity Based Costing

\begin{tabular}{|c|c|c|c|c|}
\hline \multicolumn{5}{|c|}{ System } \\
\hline No. & Cost Pool & $\begin{array}{c}\text { Tarif Cost Pool } \\
(R p)\end{array}$ & $\begin{array}{c}\text { Cost } \\
\text { Driver }\end{array}$ & $\begin{array}{l}\text { Total } \\
\text { (Rp) }\end{array}$ \\
\hline \multicolumn{5}{|c|}{ Paket W } \\
\hline 1 & Cost Pool I & 82.000 & 69 & 5.658 .000 \\
\hline
\end{tabular}




\begin{tabular}{llrcr}
\hline 2 & Cost Pool II & 5.476 & 80 & 438.080 \\
\hline 3 & Cost Pool III & 17 & 2333 & 39.661 \\
\hline $4 \quad$ Cost Pool IV & 792.857 & 3 & 2.378 .571 \\
\hline $5 \quad$ Cost Pool V & 450.000 & 24,6 & 11.070 .000 \\
\hline Total biaya tidak langsung & & & 19.584 .312 \\
\hline Total biaya langsung & & & 2.715 .000 \\
\hline Total biaya untuk paket $\mathrm{w}$ & & & 22.299 .312 \\
\hline Jumlah biaya alat gps & & & 20.010 .000 \\
\hline Jumlah paket terjual & & & 69 \\
\hline Harga pokok paket $\mathrm{w}$ & & & 613.178 \\
\hline
\end{tabular}

Paket E

\begin{tabular}{clrrr}
1 & Cost Pool I & 82.000 & 55 & 4.510 .000 \\
\hline 2 & Cost Pool II & 5.476 & 65 & 355.940 \\
\hline 3 & Cost Pool III & 17 & 2333 & 39.661 \\
\hline 4 & Cost Pool IV & 792.857 & 2 & 1.585 .714 \\
\hline 5 & Cost Pool V & 450.000 & 24,6 & 11.070 .000 \\
\hline Total biaya tidak langsung & & & 17.561 .315 \\
\hline Total biaya langsung & & & 2.125 .000 \\
\hline Total biaya untuk paket w & & & 19.686 .315 \\
\hline Jumlah biaya alat gps & & & 20.625 .000 \\
\hline Jumlah paket terjual & & & 55 \\
\hline Harga pokok paket E & & & 732.933 \\
\hline
\end{tabular}

\begin{tabular}{|c|c|c|c|c|}
\hline \multicolumn{5}{|c|}{ Paket G } \\
\hline 1 & Cost Pool I & 82.000 & 49 & 4.018 .000 \\
\hline 2 & Cost Pool II & 5.476 & 65 & 355.940 \\
\hline 3 & Cost Pool III & 17 & 2334 & 39.678 \\
\hline 4 & Cost Pool IV & 792.857 & 2 & 1.585 .714 \\
\hline 5 & Cost Pool V & 450.000 & 24,8 & 11.160 .000 \\
\hline \multicolumn{3}{|c|}{ Total biaya tidak langsung } & & 17.119 .654 \\
\hline \multicolumn{3}{|c|}{ Total biaya langsung } & & 1.815 .000 \\
\hline \multicolumn{3}{|c|}{ Total biaya untuk paket $\mathrm{w}$} & & 18.934 .654 \\
\hline \multicolumn{3}{|c|}{ Jumlah biaya alat gps } & & 22.825 .000 \\
\hline \multicolumn{3}{|c|}{ Jumlah paket terjual } & & 49 \\
\hline \multicolumn{3}{|c|}{ Harga pokok paket $g$} & & 852.238 \\
\hline
\end{tabular}

Tabel 7 memberikan hasil tarif cost pool per unit yang diperoleh dari jumlah tarif cost pool dibagi dengan pemakaian cost driver. Tarif per unit pada cost pool I sebesar Rp 82.000, cost pool II sebesar Rp 5.476, cost pool III sebesar Rp 17, cost pool IV sebesar Rp 792.857, sedangkan cost pool V sebesar Rp 450.000.

Setelah ditentukan tarif cost pool per unit maka dapat ditentukan harga pokok jasa pemasangan gpsnya. Dari tabel 8 dapat dilihat hasil perhitungan harga pokok jasa pemasangan gps dengan metode activity based costing system pada setiap paket. Harga pokok pada paket w yaitu sebesar Rp 613.178, harga pokok paket e sebesar Rp 732.933, sedangkan harga pokok paket g yaitu sebesar Rp 852.238.

Perbandingan Perhitungan Harga Pokok Jasa Pemasangan GPS menggunakan Activity Based Costing System dengan Metode Akuntansi Biaya Tradisional yang Diterapkan oleh PT SLI

Hasil perhitungan harga pokok jasa pemasangan gps dengan metode activity based costing system pada tabel 8 menunjukkan perbedaan harga pokok dengan metode akuntansi biaya tradisional yang diterapkan PT SLI. Perbedaan tersebut dapat dilihat pada tabel 9. 
Tabel 9 Perbandingan Harga Pokok Jasa Pemasangan Menggunakan Metode Activity Based Costing System dan Metode Akuntansi Biaya Tradisional oleh PT SLI

\begin{tabular}{cccc}
\hline Paket & $\begin{array}{c}\text { Harga Pokok PT SLI } \\
(\mathrm{Rp})\end{array}$ & $\begin{array}{c}\text { Harga Pokok Metode } \\
\text { ABC }(\mathrm{Rp})\end{array}$ & $\begin{array}{c}\text { Selisih } \\
(\mathrm{Rp})\end{array}$ \\
\hline $\mathrm{W}$ & 650.000 & 613.178 & 36.822 \\
\hline $\mathrm{E}$ & 750.000 & 732.933 & 17.067 \\
\hline $\mathrm{G}$ & 900.000 & 852.238 & 47.762 \\
\hline
\end{tabular}

Sumber: data diolah

Berdasarkan tabel 9 dapat dilihat perbandingan hasil perhitungan harga pokok dengan metode activity based costing system dan metode akuntansi biaya tradisional yang diterapkan oleh PT SLI. Hasil perhitungan harga pokok jasa menggunakan metode activity based costing system lebih rendah (understate) dibandingkan dengan metode akuntansi biaya tradisional yang diterapkan PT SLI dengan selisih untuk paket $w$ sebesar Rp 36.822, paket e sebesar Rp 17.067, sedangkan paket g yaitu sebesar Rp 47.762 .

Terjadinya perbedaan hasil dalam perhitungan harga pokok jasa pemasangan gps dengan metode activity based costing system dan akuntansi biaya tradisional yang diterapkan PT SLI karena adanya faktor-faktor biaya yang tidak dimasukkan dalam perhitungan yang dilakukan PT SLI dan berdampak pada kesalahan dalam pengalokasian biaya-biaya yang dibebankan dalam satu jenis cost driver saja, sehingga menyebabkan terjadinya distorsi biaya atau kesalahan pembebanan biaya yang terlalu tinggi atau terlalu rendah pada suatu objek.

Pada penerapan activity based costing system atau ABC dalam pembebanan biaya overhead dibebankan pada banyaknya cost driver sesuai dengan jumlah konsumsi aktivitas pada suatu jasa. Sehingga dapat mengalokasikan aktivitas biaya pada setiap jasa pemasangan gps dengan tepat berdasarkan konsumsi masing-masing.

Hasil penelitian ini sejalan dengan penelitian yang dilakukan oleh Kustiningsih dkk., (2017) dalam penelitian yang berjudul: Implementasi Activity Based Costing dalam Upaya Penetapan Tarif Tindakan Operasi (Studi Kasus Di RS Royal Surabaya). Dalam penelitian ini menghasilkan bahwa sistem ABC mampu mengalokasikan biaya dalam tindakan operasi menjadi lebih akurat daripada metode konvensional yang digunakan RS Royal Surabaya serta memberikan hasil perbedaan sebesar Rp 281.527.290,89. Penelitian yang dilakukan oleh Aulia dan Astuti (2018) yang berjudul: Usulan Model Perhitungan Harga Pokok Jasa Pada Industri Tour \& Travel dengan Metode Activity Based Costing (Studi Pada Perusahaan Jasa XYZ Travel) memberikan hasil bahwa dengan menggunakan metode $\mathrm{ABC}$ harga pokok untuk setiap paket menjadi lebih kecil daripada menggunakan metode yang digunakan pihak XYZ Travel. Serta penelitian yang dilakukan Kindangen dkk., (2018) yang berjudul: Penerapan Activity Based Costing System Dalam Penentuan Harga Pokok Tarif Penyewaan Jasa Kendaraan Pada PT. Serasi Autoraya juga menghasilkan bahwa Metode ABC memberikan harga pokok lebih rendah daripada menggunakan perhitungan dari PT. Serasi Autoraya dengan selisih pada mobil Avanza Rp 1.864.750 dan jenis Innova sebesar Rp 1.313.328.

Hal ini dapat disimpulkan bahwa terdapat perbedaan hasil perhitungan harga pokok jasa pemasangan gps menggunakan metode activity based costing system dengan menggunakan metode akuntansi biaya tradisional yang diterapkan oleh PT SLI

\section{KESIMPULAN}

Berdasarkan hasil penelitian dan pembahasan yang dilakukan oleh peneliti mengenai perhitungan harga pokok jasa pemasangan gps pada PT SLI dapat disimpulkan bahwa adanya perbedaan harga pokok jasa pemasangan gps menggunakan metode activity based costing system dengan metode akuntansi biaya tradisional yang diterapkan oleh PT SLI. Penggunaan metode activity based costing system dalam perhitungan harga pokok jasa pemasangan gps akan menghasilkan harga pokok yang akurat.

Metode activity based costing system memberikan harga pokok yang lebih rendah sehingga dapat memenuhi kebutuhan manajemen dalam pengambilan keputusan pada 
strategi untuk memenangkan persaingan antar kompetitor. Meningkatkan kualitas layanan dalam jasa pemasangan gps dan memberikan harga yang lebih rendah dari kompetitor lain akan menarik konsumen, hal tersebut akan berdampak pada tingginya tingkat penjualan jasa pemasangan gps yang akan memberikan laba yang lebih besar pula bagi PT SLI. Sehingga diharapkan metode activity based costing system ini menjadi pertimbangan dalam menentukan harga pokok jasa pemasangan gps pada PT SLI.

\section{Keterbatasan dan rekomendasi untuk penelitian selanjutnya}

Keterbatasan penelitian ini adalah sulitnya dalam penentuan cost driver dan tidak diberikannya data perhitungan harga pokok jasa pemasangan gps secara detail dan jelas. Peneliti hanya diberikan hasil secara keseluruhan dan dianalisis berdasarkan wawancara dan data yang diperoleh. Sehingga rekomendasi untuk penelitian selanjutnya diharapkan mencari lebih dalam mengenai data yang berkaitan dengan penelitian melalui teknik pengumpulan data yang lain serta melakukan penelitian pada bidang jasa yang lainnya

\section{DAFTAR PUSTAKA}

Aulia, K. P., \& Astuti, M. (2018). USULAN MODEL PERHITUNGAN HARGA POKOK JASA PADA INDUSTRI TOUR \& TRAVEL DENGAN METODE ACTIVITY BASED COSTING (ABC)(Studi Pada Perusahaan Jasa XYZ Travel). In National Conference of Creative Industry.

Bagaimana Penerapan Sistem Activity Based Costing Pada Perusahaan Jasa. Diambil 7 Mei 2021. Dari https://www.dictio.id/t/bagaimana-penerapan-sistem-activity-based-costing-padaperusahaan-jasa/12831

Hidayat, R. R. (2018). Pengaruh Harga dan Kualitas Produk terhadap Keputusan Pembelian (Studi Kasus Pada Pembeli Gula Aren Sawit di Desa Simpang Empat Kecamatan Sei Rampah Kabupaten Sergai Provinsi Sumut). Doctoral dissertation, Universitas Islam Negeri Sumatera Utara.

Kindangen, F., Morasa, J., \& Mawikere, L. M. (2018). Penerapan Activity Based Costing System Dalam Penentuan Harga Pokok Tarif Penyewaan Jasa Kendaraan Pada Pt. Serasi Autoraya. GOING CONCERN: JURNAL RISET AKUNTANSI, 13(04).

Kustiningsih, N., Atmadja, S. S., \& Patmana, O. (2017). Implementation Of Activity Based Costing System In Making Affort To Determine The Tariff Of Operation Action (Case Study In Surabaya Royal Hospital). Archives of Business Research, 5(11).

Mulyadi (2015). Akuntansi Biaya, Edisi 5. Yogyakarta: Sekolah Tinggi Ilmu Manajemen YKPN

Narko, H. (2016). FAKTOR-FAKTOR YANG MEMPENGARUHI PENETAPAN HARGA JUAL BENSIN MURNI ECERAN (Studi Kasus Pada Penjual Bensin Eceran Di Kecamatan Grabag Magelang).Doctoral dissertation, IAIN Salatiga.

Pulungan, R. Z. (2017). Perhitungan Unit Cost dengan Metode Activity Based Costing (ABC) Sebagai Alternatif Penentuan Tarif Rawat Inap RSUD Kabupaten Tapanuli Selatan Tahun 2017. Universitas Sumatera Utara.

Sugiyono (2015). Metode Penelitian Kuantitatif, Kualitatif, dan R\&D. Bandung: Alfabeta, CV.

Tjiptono, F. \& Chandra Greforius, C. (2016). Pemasaran Jasa (Prinsip, Penerapan, dan Penelitian). Yogyakarta: Andi 